\title{
Vibration damping composition polymer materials and coatings for engineering purpose
}

\author{
Soyibjon Negmatov, $T$ Ulmasov, Farxod Navruzov ${ }^{*}$, and $S$ Jovliyev \\ State Unitary Enterprise "Fan va tarakkiyot" at Tashkent State Technical University named after \\ I.Karimov, Tashkent, Uzbekistan
}

\begin{abstract}
To develop and create effective vibration-damping composite polymer materials (VDCPM) with high viscoelastic and strength properties, the choice of research objects to increase durability reduces vibration of parts and structures of machines consequently, the noise level in industrial premises is stated and substantiated. A method is described for studying the viscoelastic properties, adhesive strength, microhardness, impact strength of polymer coatings, and compositions based on them, filled with organomineral ingredients. The results of studies of the viscoelastic and physicomechanical properties of polymer composite materials based on epoxy polymers and an organomineral filler - rubber powder are presented. Based on complex analyzes and the obtained results of the study of the physicomechanical and viscoelastic properties of materials, several effective compositions of vibration-damping polymer materials using rubber powder have been developed.
\end{abstract}

\section{Introduction}

At the present stage of the development of technology, the fight against vibration and noise in production is an urgent task since the reliability and durability of machines and mechanisms are inextricably linked with their vibrational behavior [1-3]. The most effective among the existing methods of dealing with noise and vibration is the use of the ability of vibration-damping polymeric materials, which have increased internal losses of vibrational energy during their deformation and sufficiently high elasticity [4-15].

In recent years, in the science of polymers, one of the first places has been the problem of creating polymer composite materials (PCM) with specified properties, in particular, vibration-damping characteristics. The development of a scientific basis for obtaining such materials is of fundamental importance; it allows you to significantly expand the range of polymeric materials and their properties based on polymers created and produced by industry using their physical modification. Physical modification of known polymers, their combination with ingredients of a different nature, of a different structure, is one of the promising ways to create effective polymer compositions with desired properties, including viscoelastic ones $[12,16]$.

In this regard, it becomes necessary to develop new effective vibration damping materials based on polymer compositions.

*Corresponding author: navrozovf@gmail.com 
As is known $[17,18]$ for the development of composite polymer materials with high viscoelasticity and strength properties, first of all, it is necessary to select the required polymers and fillers.

This work aims to study the viscoelastic and strength properties and the development of effective discharge-damping polymer composite materials based on thermosetting polymers and organomineral filler-rubber powder, the selection, and substantiation of the research object, the methods of obtaining and determination of vibration damping, physicalmechanical and thermophysical properties of the developed composite polymer materials operating under vibration conditions are also considered.

\section{Methods}

Based on the foregoing, epoxy, furan, and shale polymers were chosen as the object of research ED-16, ED-20 (State Standart 10587-76), FAED-20 (TC 59-02.039.13-78) and EDSH-1 (TC 38-1091-76), as well as powdered elastomers PE-R (rough) and PE-E (extrusion), plasticizer dibutyl phthalate (DBP), polyethylene polyamine hardener (PEPA).

The research methodology for vibration damping and physical and mechanical properties of composite polymer materials was carried out as follows. The viscoelastic properties of the obtained samples were studied by the resonance cavity width method [1, 13].

The microhardness of composite polymer coatings was determined using a PMT-3 device, which is a microscope with a device for pressing the indenter into the test material under a certain static load $[19,20]$.

The impact strength of polymer coatings was determined using a U-2 device, which is a vertical pile driver [19]. The thickness of the coatings was measured with a TIP-10 magnetic thickness gauge.

To study the thermophysical properties, in particular, to determine the thermal conductivity coefficient, a stationary method for determining the heat flux at room temperature was used - the heat measurement method.

The temperature dependence of the thermal conductivity of the studied polymers and composites based on them was studied by the dynamic method, [21] which, the experimental determination of thermal conductivity, the compositions under study were carried out in the temperature range (240-500 K) according to State Standart 23630.2-79 on an IT-Ya-400 device, one of the few devices for thermophysical research produced by the industry of the Russian Federation.

\section{Results and Discussion}

First of all, the adhesive-strength and vibration-damping properties of polymers were investigated. It has been established $[22,23]$ that the modification of epoxy polymers with polymer fillers, inferior in strength to the binder, for example, vulcanized rubbers, can significantly increase the impact strength and viscoelastic properties of the compositions. Such vulcanized rubbers include crushed rubber powder from waste rubber products and worn-out automotive tires after appropriate processing (grinding).

In this regard, as given above, as a polymer filler for rigid-chain polymers, rubber powders were selected that differ from each other in the grinding method. For curing oligomers ED-16, ED-20, FAED-20, and EDSH-1, polyethylene polyamine - PEPA (TC 608-594-70) were chosen, and for plasticization - dibutyl phthalate- DBP [1]. It should be noted that the viscoelastic properties of materials were studied by determining the 
logarithmic decrement $[\delta]$, and the criterion was determined by the product of the logarithmic decrement and the modulus of elasticity $\left[\delta . \mathrm{E}^{\prime}\right][1,12,13]$.

The study of the viscoelastic properties of composites based on the ED-16 epoxy polymer, depending on the content of rubber powder crushed on an extruder [24], showed that this dependence is extreme (Fig. 1). The logarithmic decrement increases with an increase in the content of rubber powder in the system and passes through a maximum at 40-45 m.p. filler without low molecular weight plasticizer DBP. In the presence of DBP, up to 10 m.p. the maximum of the logarithmic decrement is observed at $40-45$ m.p. rubber powder. In this case, the intensity of the increase in mechanical losses is greater than without DBP.

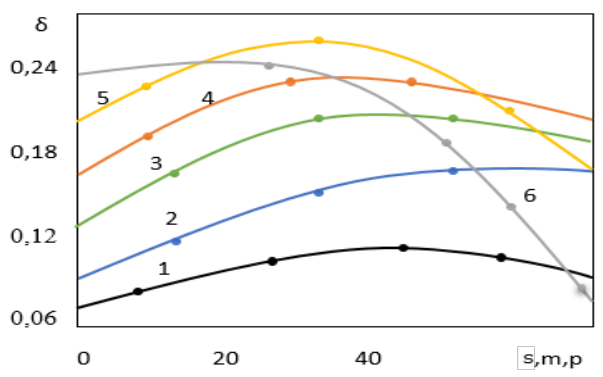

Fig.1. Dependence; of the decrement of vibrations of the epoxy composition on the content of rubber at different content of DBP, Content DBP, $1-0 ; 2-10 ; 3-15 ; 4-20 ; 5-25,6-30,6-30 ;$ Mass, p.

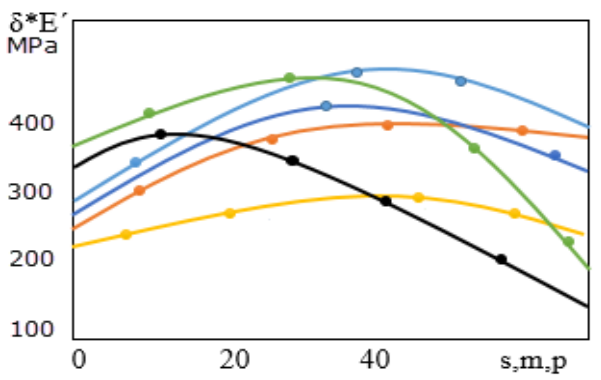

Fig.2. Dependence of the parameter $\delta \mathrm{E}$ of the epoxy composition on the content of rubber powder, Content DBP, 1-0; 2-10; 3-15; 4-20; 525; Mass, $\mathrm{p}$

This is probably because in the presence of DBP, the filler surface is well wetted with the binder. However, with an increase in the proportion of low-molecular-weight plasticizer up to 30 parts by weight, the maximum of the logarithmic decrement shifts towards lower concentrations of rubber powder. With DBP 15, 20, 25, 30 m.p., the maximum losses of the system are observed, respectively, at 40,35, 30, and $15 \mathrm{~m} . \mathrm{p}$. of rubber powder. This phenomenon is apparently due to the deterioration of the interaction between the rubber powder and the binder; that is, with the DBP content, the interaction between the binder and the filler surface deteriorates since the surface will be wetted with DBP and not resin. With an increase in the content of rubber powder in the system, the amount of DBP plasticizer spent on wetting its surface increases. The proportion of DBP that creates the effect of inter-bundle plasticization is reduced to a minimum, and antiplasticization of the composition will take place, that is, an increase in the strength of the binder. As a result, the mechanical losses in the system are reduced. Considering the effectiveness of vibration damping material and coatings based on them, it is estimated by the product of the logarithmic decrement of vibrations by the dynamic modulus of elasticity - $\delta \mathrm{E} '[1]$, then the effect of rubber powder on it was studied.

Indicator dependence analysis $\delta \mathrm{E}$ on the content of rubber powder showed that with an increase in the proportion of filler in the system, an increase in $\delta \mathrm{E}^{1}$, and it passes through a maximum at 40 m.p. filler (fig 2.) in the absence of DBP. At a higher DBF value $(15,20$, 25,30 m.p.), maximum $\delta \mathrm{E}^{\prime}$, as well as maximum $\delta$ (logarithmic decrement of fluctuations), is observed at lower filler contents.

The study of the temperature dependence of epoxy composites filled with rubber powder showed (Fig. 3) that the soft filler plays the role of a plasticizer; that is, the glass transition temperature of the composition shifts towards lower temperatures. If the glass transition temperature of the epoxy composition with 25 m.p. If the glass transition temperature of the epoxy composition with 25 m.p. DBP is $350 \mathrm{~K}$, then the introduction of 
30 m.p. rubber powder reduces Gt by $20 \mathrm{~K}$ (see Fig. 3). In this case, there is a significant increase in the logarithmic decrement of the system relative to the composition without rubber powder. This increase is over $40 \%$. This increase in mechanical losses in the presence of rubber powder is due to a significant deterioration in the adhesive bond between the binder and filler in the presence of DBP. The shift in Gt of the composition is due to a decrease in the packing density of macromolecules binder and an increase in mesh defect.

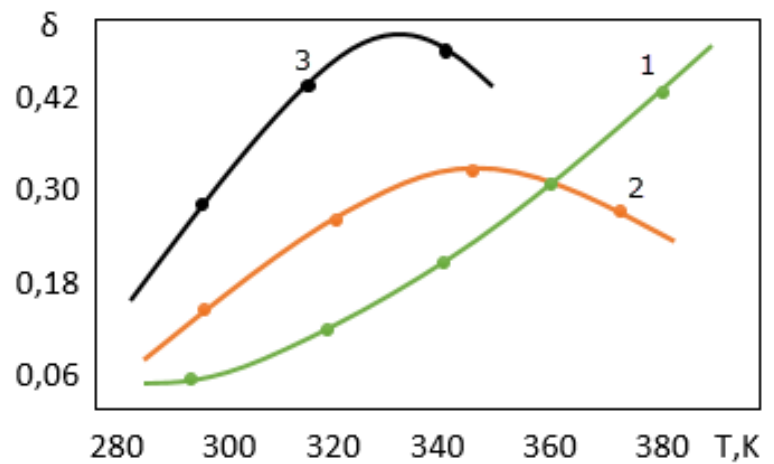

Fig 3. Temperature dependence of the decrement of vibrations of the epoxy composition.

1 is RP-0 mass, $\mathrm{p}$; 2 is DBP -25 mass, $\mathrm{p} ; 3$ is DBP $-25+\mathrm{RP}-30$ mass, $\mathrm{p}$.

The results of studies of the viscoelastic and physicomechanical properties of the compositions selected as the object of study are shown in Table 1.

Table 1. Viscoelastic and physical-mechanical properties of the developed vibration-damping composite polymer materials.

\begin{tabular}{|c|c|c|c|c|c|c|}
\hline Type of material & $\begin{array}{l}\text { Composition of developed } \\
\text { compositions }\end{array}$ & $\begin{array}{c}\delta . \mathrm{E} \\
\mathrm{MPa}\end{array}$ & $\begin{array}{l}\sigma \mathrm{A} \\
\mathrm{MPa}\end{array}$ & $\mathrm{H}_{\mathrm{m}}$ & $\begin{array}{l}\sigma i . \mathrm{p} . \\
\mathrm{MPa}\end{array}$ & $\begin{array}{c}\lambda \\
\text { At,m.k }\end{array}$ \\
\hline $\begin{array}{l}\text { VDCPM on the } \\
\text { basis of } \\
\text { ED-16 }\end{array}$ & $\begin{array}{c}\text { ED-G6-100 m.p. } \\
\text { DBP -15 m.p. } \\
\text { PEPA -12 m.p. } \\
\text { Rubber powder -40 m.p. }\end{array}$ & 385 & 28 & 136 & 4.5 & 0.22 \\
\hline $\begin{array}{l}\text { VDCPM on the } \\
\text { basis of } \\
\text { ED - } 20\end{array}$ & $\begin{array}{c}\text { ED-20-100 m.p. } \\
\text { DBP -20 m.p. } \\
\text { PEPA -12 m.p. } \\
\text { Rubber powder - } 40 \text { m.p. }\end{array}$ & 378 & 26 & 134 & 4.3 & 0.22 \\
\hline $\begin{array}{l}\text { VDCPM on the } \\
\text { basis of } \\
\text { FAED- } 20\end{array}$ & $\begin{array}{c}\text { FAE-20-100 m.p. } \\
\text { DBP -20 м.ч } \\
\text { PEPA -12 м.ч } \\
\text { Rubber powder - } 40 \text { m.p. }\end{array}$ & 370 & 25 & 130 & 4.2 & 0.20 \\
\hline $\begin{array}{l}\text { VDCPM on the } \\
\text { basis of } \\
\text { EDSH - } 1\end{array}$ & $\begin{array}{l}\text { EDSH -100 m.p. } \\
\text { DBP - } 15 \text { m.p. } \\
\text { PEPA -12 m.p. } \\
\text { Rubber powder -35 m.p. }\end{array}$ & 362 & 25 & 132 & 4.0 & 0.18 \\
\hline
\end{tabular}

From the above, it can be concluded that, in contrast to flake mineral fillers, rubber powder has a very weak effect of internal friction between filler particles. This is due to the high flexibility of this filler. 
Filling the epoxy with mineral fillers also significantly increases the impact resistance of the system. However, it should be noted (see Fig 4.) that when filled with kaolin, the impact strength of the composition passes through a maximum at a filler content of 30 m.p., and with talc 40 m.p. A decrease in $\sigma_{\text {is }}$ with the entrainment of kaolin and talc in the filler by more than 30 and 40 m.p. is apparently due to excessive loosening of the composition. Additional rubber powder to a composition filled with graphite and kaolin up to 30-40 ml. Adding additional rubber powder up to $30-40 \mathrm{ml}$ to the composition filled with graphite and kaolin increases the systems. Adding additional rubber powder up to $30-40 \mathrm{ml}$ to the composition filled with graphite and kaolin increases the $\sigma_{\text {is }}$ system. So, adding to the composition ED-16-100, DBP -15, kaolin- m.p., 40 m.p rubber powder increases the system by $15 \%$, and in the composition of the composition ED-16-100, DBP-15 and graphite 20 m.p., 30 m.p rubber powder - by $25 \%$.

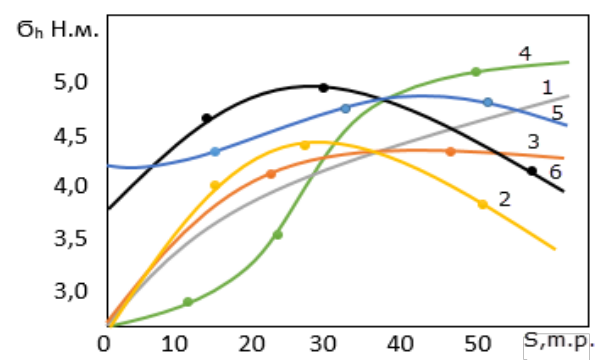

Fig.4. Dependence of the impact strength of the composition based on the oligomer ED-16 on the content of dispersed fillers. 1 is graphite; 2 is kaolin; 3 is talc; 4 is RP, 5 is kaolin-20+RP; 6 is $\mathrm{RP}+$ Graphite-20

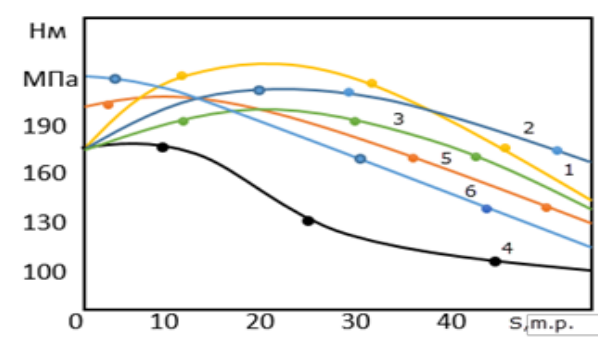

Fig. 5. Dependence of the microhardness of compositions based on oligomer ED-16 on the content of mineral dispersed fillers. 1 is graphite; 2 is kaolin; 3 is talc, 4 is RP, 5 is kaolin-20+RP; 6 is RP+ Graphite-20;

Figure 5 shows the dependence of the microhardness $\mathrm{Hm}$ of an epoxy composition based on oligomer ED-16 on the content of mineral fillers and rubber powder. It can be seen (Figure 5.) that with an increase in the content of fillers of mineral origin up to 20 m.p. there is a slight increase in Нм compositions. This is due to an increase in the flexibility of the binder chains and a decrease in the packing density of the components in the composition.

Analysis of the dependences of the product $\delta \mathrm{E}^{\prime}$ and the impact strength on the content of rubber powder made it possible to establish the presence of a close correlation between these indicators. The result of evaluating the correlation allows us to judge in further studies the impact strength of coatings by the viscoelastic properties of the composition.

Thus, by varying the type, content, and ratio of organomineral ingredients and epoxy compounds, it is possible to develop effective vibration-damping composite polymer materials for use in various machines and mechanisms, allowing them to increase their performance and efficiency, as well as reduce the noise level in industrial premises.

\section{Conclusions}

The viscoelastic properties of filled epoxy materials have been investigated. It is shown that with an increase in the filler content of rubber powder, the logarithmic decrement of the compositions first increases (up to $40 \mathrm{ppm}$ ), then decreases. This is apparently due to some increase in the flexibility of the binder chains up to 40 m.p. filler. It has been established that epoxy polymers have high adhesion and strength properties and good viscous flow characteristics, as well as manufacturability, which makes it possible to obtain 
effective vibration-damping composite materials with the addition of organomineral ingredients to their composition. It is shown that rubber powder, introduced into epoxy oligomers as a filler, has a plasticizing effect, and as a result, the glass transition temperature of the composition decreases, and their vibration damping properties improve.

\section{References}

1. Negmatov S.S., Pak I.I., Damping properties of polymer materials and coatings based on them. UzIIINTI, Tashkent, p 16. (1974)

2. Negmatov S. S., Pak I. I., Application of polymer composite coatings in a cotton harvesting machine. In the collection of scientific works of Tashpi. "Agricultural machines" issue (329), Tashkent, p. 125-127. (1982).

3. Pisarenko G.S. Energy dissipation during mechanical vibrations. Kiev, Publishing House, Academy of Sciences of the Ukrainian SSR, (1962).

4. Vibration damping material NOISEBUSTER [Electronic resource], NOISEBUSTER, 2015. URL, http,,www.noisebuster-msk.ru,. (Date of access, 03, 15, 2015). (2015)

5. Pat. 2188214 Russian Federation, MPK7 C08L95, 00, B32B11, 02, B60R13, 08.

6. Pat. 2235106 Russian Federation, MPK7 C08L95 , 00, C08L23 , 22, C08L91 , 00, C08L93 , 00, C08KZ, 04, G08K7, 18.

7. Pat. 2285023 Russian Federation, IPC G08L75, 08 B32B27, 40. Polymer vibrationabsorbing composition and layered vibration-absorbing material based on it, Sitiy Yu. V., Kislyakova V.I., Ananiev V.K., etc .; applicant and patentee FSUE "VIAM" № 200510B140, 04; declared 02,09,05; publ. 10.10.06, Bul. № 8. p 8 .

8. Pat. 2368630 Russian Federation, IPC C08L95, 00, S08KZ, 26. Vibration and noise absorbing sheet material, Litus A. A., Sinitsha I.N., and others; applicant and patentee Saratov state. those. univ. - № 2008112756, 04; declared 04, 02, 08; publ. 09, 27, 09, Bul. (27) .p7p.

9. Pat. 2375398 Russian Federation, IPC C09D131, 04. Vibration-absorbing mastic, Rodionov A. G., Volkov V. N., Kaptsan A. S .; applicant and patentee Rodionov A. G., Volkov V. N., Kaptsan A. S. - № 2007148964,04; declared 12,25,2007; publ. 10.12.2009, Bul. № 34.p 14 . (2009).

10. Matveev V.V. To the definition of damping properties with amplitude-dependent resistance. "Problems of Strength", (5), pp. 11-17. (1970).

11. Vibration damping material NOISEBUSTER [Electronic resource], (Date NOISEBUSTER, 2015.URL, http, www.noisebuster-msk.ru,. Address, 03. (15) 2015). (2015).

12. Jovliev S.S., Negmatov S.S., Abed N.S., Ulmasov T.U., Bozorboev Sh.A., Eminov Sh.O. Vibration-damping composite polymeric materials and methods for studying their damping and physical and mechanical properties, Composite materials, Tashkent, (1), - p.26-29.( 2016).

13. Experimental setup for studying the damping properties of structural plastics. In the collection of materials on the results of research works of the Faculty of Chemistry and Technology of TASHPI for 1970., vsh. № 74, ser. chem., Tashkent, (1971).

14. ISO 527-1,2012 Plastics-Determination of Tensile Properties-Part 1, General Principles. ISO; Geneva, Switzerland, (2012).

15. Jose J.P., Thomas S., Kuruvilla J., Malhotra S.K., Goda K., Sreekala M.S. Polymer Composites. Volume 1. Wiley; Weinheim, Germany, 2012. Advances in polymer composites, Macro- and microcomposites-State of the art, new challenges, and opportunities; pp.3-16. (2012).

16. Jovliev S.S., Abed N.S., Negmatov S.S., Ulmasov T.U., Saidakhmedov R.Kh., Atakhozhaev A., Sattorov A.R., Physical features of thermosetting vibration- 
absorbing polymers as structural materials, "Republican Scientific and Technical Conference". pp.421-422. (2018).

17. Jovliev S.S., Negmatov S.S., Abed N.S., Ulmasov T.U., Sattorov A.R. Research and development of vibration-absorbing composite polymeric materials and coatings based on them, Composite materials, Tashkent,. (1), p.42. (2018)

18. Jovliev S.S., Negmatov S.S., Abed N.S., Ulmasov T.U., Bozorboev Sh.A., Eminov Sh.O. Vibration-absorbing composite polymeric materials and methods of studying their damping and physical and mechanical properties, "Prospects for the development of composite and nanocomposite materials", (1), pp.26-28. (2016).

19. M. L. Kerber, V. M. Vinogradov, G. S. Golovkin, et al. Polymer composite materials, structure, properties, technology, textbook. handbook,; ed. by A. A. Berlin. - St. Petersburg, Profession, p 560 .(2008).

20. Abed N.S., Negmatova K.S., Ulmasov T.U., Negmatov J.N., Eminov Sh.O., Bozorboev Sh.A., Jovliev S.S., Sattorov A.R., Dadamukhamedova N.A. Research to obtain compositions by mixing granular-powder organomineral ingredients on a continuous installation, Composite materials, Tashkent,. (2), p. 53.(2017).

21. Nielsen, L. Mechanical properties of polymers and polymer compositions. - M., Chemistry, (2). p 301. (1978)

22. V.A. Kabanova. Encyclopedia of Polymers, - M., Soviet Encyclopedia, (1977).

23. Nikiforov A. C. The state and trends in the use of vibration - absorbing means in industry and transport for protecting a person from the harmful effects of vibration and noise,

24. A. C. Nikiforov, Application of vibration-absorbing and vibration-extinguishing means in industry and transport, Mater.Krabtkortnogo seminar, Leningrad, March 1314, 1984-L, p. 6-10. (1984).

25. Z.N. Grozinskaya, P.I. Teeth. Thermal aging of epoxy coatings in an organic environment "Paints and varnishes and their application" (5). (1965) 